\title{
Cardiac mesoangioblasts are committed, self- renewable progenitors, associated with small vessels of juvenile mouse ventricle
}

\author{
BG Galvez ${ }^{1}$, M Sampaolesi ${ }^{1,2}$, A Barbuti ${ }^{3}$, A Crespi $^{3}$, D Covarello ${ }^{1}$, S Brunelli ${ }^{1,4}$, A Dellavalle ${ }^{1}$, S Crippa ${ }^{1}$, G Balconi ${ }^{5}$, I Cuccovillo ${ }^{5}$, \\ F Molla ${ }^{5}$, L Staszewsky ${ }^{5}$, R Latini ${ }^{5}$, D DiFrancesco ${ }^{3}$ and G Cossu $^{\star, 1,6,7}$
}

Different cardiac stem/progenitor cells have been recently identified in the post-natal heart. We describe here the identification, clonal expansion and characterization of self-renewing progenitors that differ from those previously described for high spontaneous cardiac differentiation. Unique coexpression of endothelial and pericyte markers identify these cells as cardiac mesoangioblasts and allow prospective isolation and clonal expansion from the juvenile mouse ventricle. Cardiac mesoangioblasts express many cardiac transcription factors and spontaneously differentiate into beating cardiomyocytes that assemble mature sarcomeres and express typical cardiac ion channels. Cells similarly isolated from the atrium do not spontaneously differentiate. When injected into the ventricle after coronary artery ligation, cardiac mesoangioblasts efficiently generate new myocardium in the peripheral area of the necrotic zone, as they do when grafted in the embryonic chick heart. These data identify cardiac mesoangioblasts as committed progenitors, downstream of earlier stem/progenitor cells and suitable for the cell therapy of a subset of juvenile cardiac diseases.

Cell Death and Differentiation (2008) 15, 1417-1428; doi:10.1038/cdd.2008.75; published online 23 May 2008

Several acute or chronic cardiac diseases are characterized by progressive expansion of the left ventricular chamber, with replacement by fibrous deposition in the ventricular wall. One approach proposed for reverse myocardial remodeling is regeneration of cardiac myocytes using stem cells. ${ }^{1}$ On the basis of distinct cell surface markers such as Sca-1 or c-Kit, different cardiac stem-like cells have been isolated that can restore cardiac function after ischemic injury. ${ }^{2,3}$ None of these cells shows spontaneous cardiac differentiation and they also differentiate into other tissue types of the heart. ${ }^{2-5}$ On the other hand, Isl-1 expressing progenitors appear to be committed to cardiac differentiation but still require interactions with other cells for both proliferation and differentiation. ${ }^{4}$

It is also becoming clear that a significant part of the beneficial effect that most of these cells exert on the infarcted heart is due to the secretion of factors that increase survival of residual myocardium and/or favor angiogenesis. ${ }^{6}$ This was for example the case of embryonic mesoangioblasts whose transplantation resulted in a 50\% recovery of cardiac function but whose differentiation into new cardiomyocytes was rare. ${ }^{7}$

Our recent work on mesoangioblasts isolated from postnatal skeletal muscle,,$^{8,9}$ indicated that these cells, possibly because of a local commitment, exhibit efficient differentiation into skeletal muscle. On this basis, we isolated meso- angioblast-like cells from different regions of the post-natal mouse heart.

Here we describe the isolation, through a specific explant culture method, of self-renewing committed cardiac progenitors from different regions of the juvenile heart. These cells, operationally termed 'cardiac mesoangioblasts', show a unique phenotype and high spontaneous cardiomyocyte differentiation; they can be expanded in vitro to numbers suitable for systemic delivery, and, upon transplantation into the infarcted heart, differentiate into new, cardiomyocytes.

\section{Results}

Isolation and in vitro expansion of cells from cardiac biopsies. Hearts were collected from 4-week-old GFP or wt mice and under a dissecting microscope, aortic outflow tract, ventricle or atrium were isolated and further dissected into small fragments and plated on $1 \%$ gelatin coated dishes as previously described. ${ }^{10}$ After an initial outgrowth of fibroblastlike cells, small round and poorly adhering cells appeared and could be detached by gently pipetting (Figure 1a). Floating cells were cloned by limiting dilution. At low density, clones acquired a triangular, refractile morphology while

\footnotetext{
${ }^{1}$ Stem Cell Research Institute, San Raffaele Scientific Institute, Milan, Italy; ${ }^{2}$ Department of Experimental Medicine, University of Pavia, Pavia, Italy; ${ }^{3}$ Department of Biomolecular Sciences and Biotechnology, University of Milan, Milan, Italy; ${ }^{4}$ Department of Experimental Medicine, University of Milano-Bicocca, Milano-Bicocca, Italy; ${ }^{5}$ Department of Cardiovascular Research, Mario Negri Institute, Milan, Italy; ${ }^{6}$ Department of Biology, University of Milan, Milan, Italy and ${ }^{7}$ San Raffaele Biomedical Park of Rome, Rome, Italy

${ }^{*}$ Corresponding author: G Cossu, Stem Cell Research Institute, San Raffaele Scientific Institute, Dibit, H San Raffaele, Via Olgettina 58, 20132 Milan, Italy. Tel: + 39022643 4954; Fax: + 39022643 4621;

E-mail: cossu.giulio@ hsr.it

Keywords: cell therapy; cardiovascular diseases; perycytes

Abbreviations: ANF, atrial-natriuretic-peptide; AP, alkaline phosphatase; SMA, smooth $\alpha$ actin; vWF, von Willebrand factor; CAL, coronary artery ligation; HH, Hamilton Hamburger

Received 26.2.08; revised 10.4.08; accepted 17.4.08; Edited by RA Knight; published online 23.5.08
} 
a
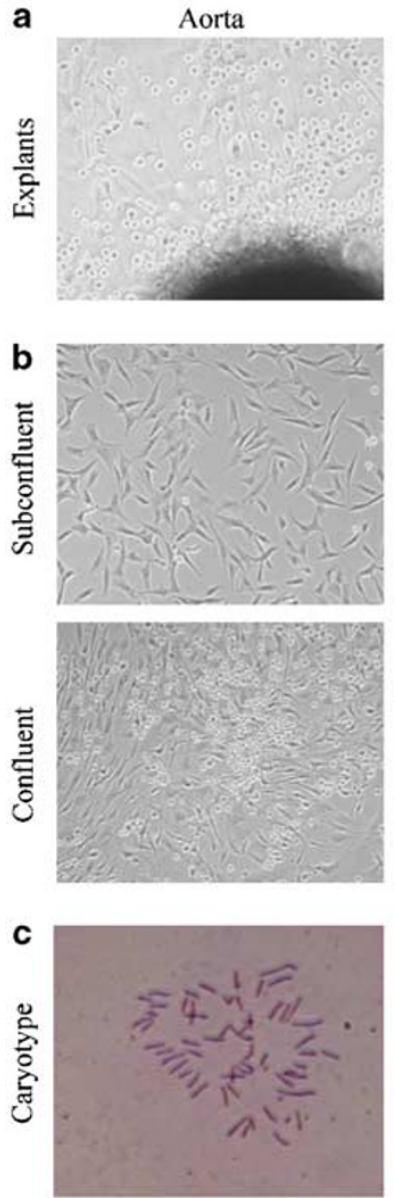
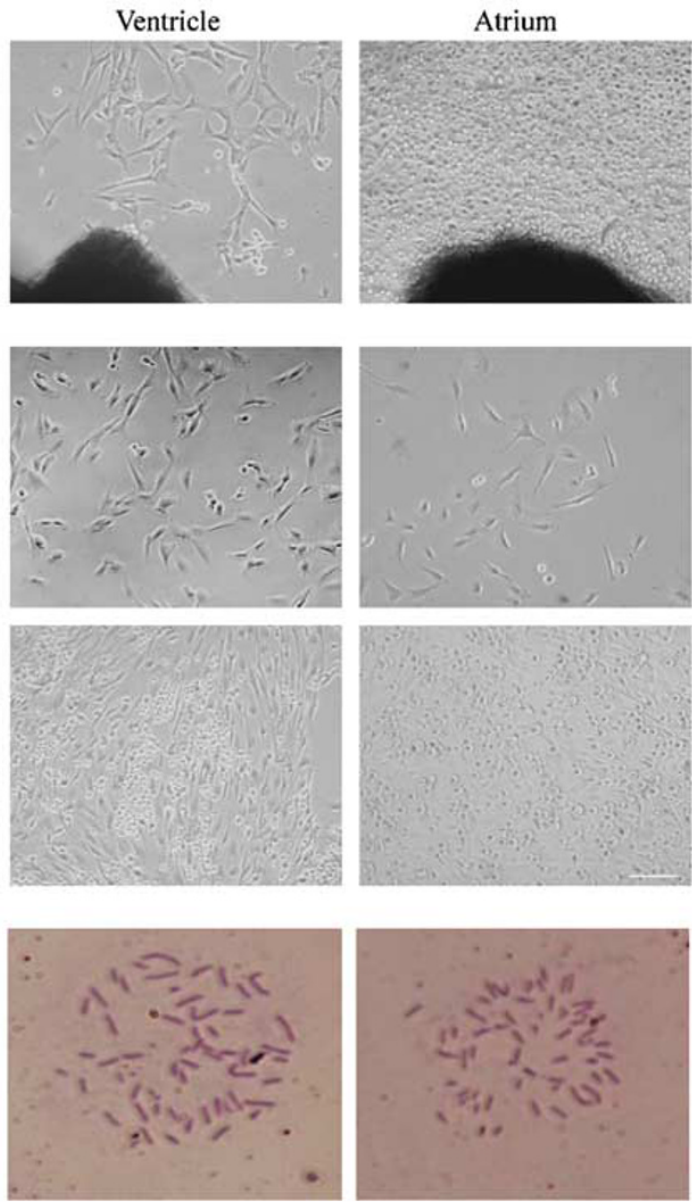
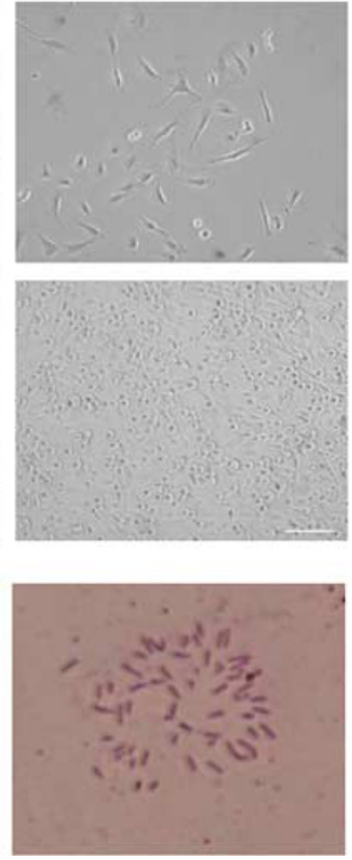

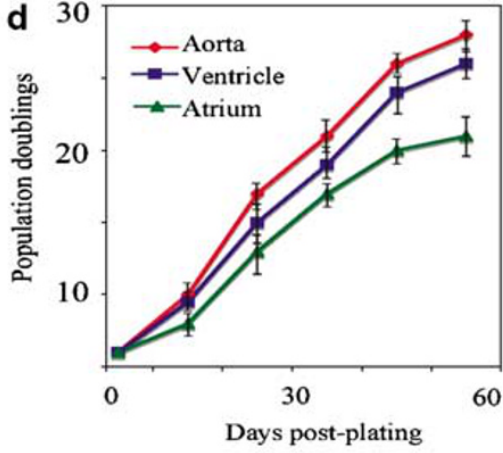

e
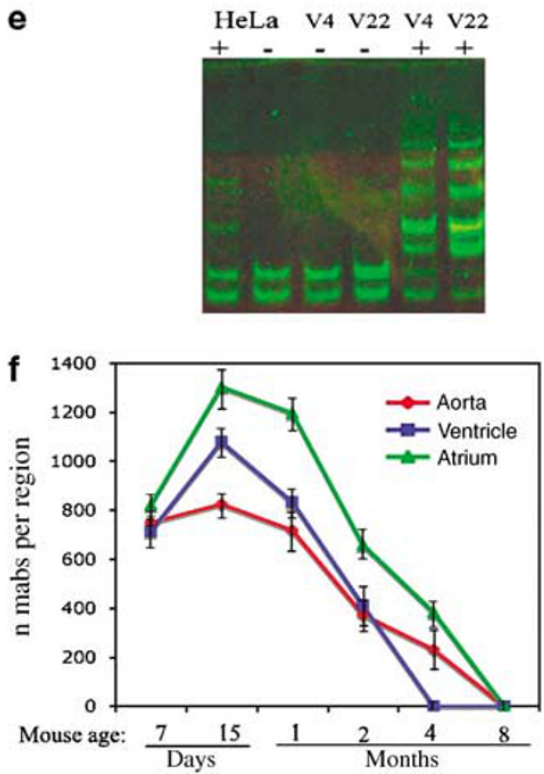

Figure 1 Adult cardiac mesoangioblasts isolated from explants of different heart regions. (a) Phase contrast morphology of the cellular outgrowth from fragments of aorta, ventricle or atrium of adult mice hearts. Note the presence of rounded and refractile cells on top of the fibroblasts layer; bar, $50 \mu \mathrm{m}$. (b) Phase contrast morphology of growing or confluent cardiac mesoangioblasts isolated from aorta, ventricle and atrium after five passages in vitro. Bar: $50 \mu \mathrm{m}$. (c) Caryotype of cardiac mesoangioblasts after16 passages, showing a normal number of chromosomes. (d) Proliferation curves of the three different cardiac mesoangioblasts in complete medium. At the time of cell isolation from the explant, cell populations were considered to be at 1 population doubling (PD). Note that aorta or ventricle mesoangioblasts have a higher proliferation rate than those from atrium $(P<0.05)$. (e) Example of Telomerase activity of cardiac mesoangioblasts isolated from ventricle after 4 (V4) or 22 (V22) population doublings. HeLa cells are also shown as a positive control in the left side; for each sample $(+)$ a negative control $(-)$ has been used exposing the protein extracts to high temperature for telomerase enzyme degradation. (f) Average number of cardiac mesoangioblasts isolated from hearts of mice at different age. Differences are statistically significant $(P<0.05)$

several round, poorly adhering cells appeared at high density (Figure 1b); cells maintained a relatively slow proliferation rate for approximately 25 passages with a doubling time of approximately $72 \mathrm{~h}$ (Figure 1d), a normal caryotype (Figure 1c) and a constant telomerase activity (Figure 1e). Aorta and ventricle-derived clones proliferated faster than atrium-derived clones (Figure 1d and b). After 25 passages, large flat cells appeared at increasing frequency that did not divide any more. We have operationally termed these cells 'ventricular, aortic or atrial mesoangioblasts'.

Cells were also isolated from different regions of the heart of mice older than 1 month: the number of cells that outgrew from each defined region and their in vitro proliferation was progressively reduced with age (Figure 1f).

Characterization of surface markers and cardiac genes expression. Adult cardiac mesoangioblasts from the different heart regions were analyzed by flow cytometry for the expression of markers. All clones expressed Sca-1 and CD44 but not CD45, while CD34, CD31 and c-kit were expressed by clones derived from aorta and ventricle but not from atrium (Figure 2a).

RNA was extracted from the different adult cardiac mesoangioblasts while proliferating $(P)$ or after 5 days of differentiation (see Materials and Methods) in appropriate medium (D). RT-PCR was performed to analyze the expression of different genes involved in cardiac development (Figure 2b). All proliferating cells expressed Isl-1 and Gata4/ 6 while only aorta- and ventricular-derived cells expressed Nkx2.5 or Conn43; surprisingly all cells expressed cardiac differentiation markers such as ANF and cardiac actin when still proliferating (see also Supplementary Table 1). Skeletal myogenic markers such as MyoD or Myf5 were not expressed in any clone. It is noteworthy that ventricle- and aorta-derived clones expressed some early endothelial markers such as CD31 and Tie-2 but not angiopoietin or vWF 

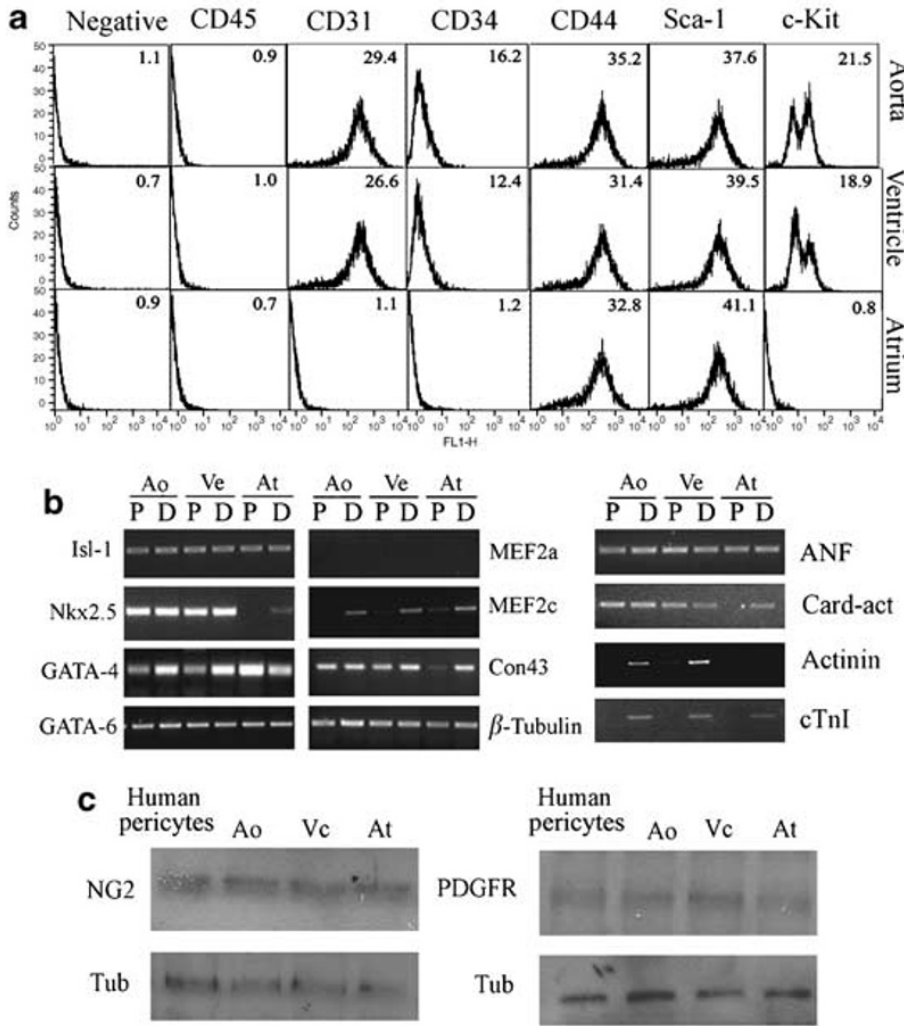

d

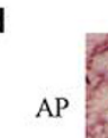

Aorta

Ventricle

Atrium

AP

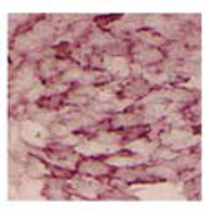

e
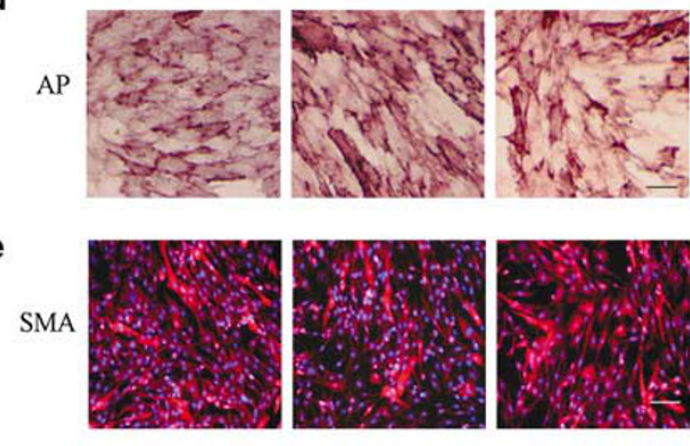

f
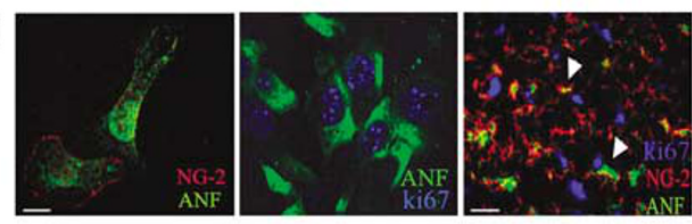

g
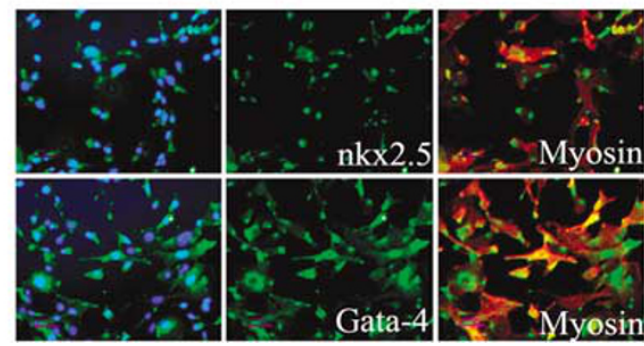

Figure 2 Expression of markers by the cardiac mesoangioblasts. (a) Surface markers expression analysis by flow cytometry. Cardiac mesoangioblasts were analyzed for the presence of CD45, CD31, CD34, CD44, Sca-1 or c-kit. (b) Expression of cardiac genes analyzed by PCR. Agarose gels are shown for the three different cardiac clones (Ao, aorta; Ve, Ventricle; At, Atrium) in either proliferation (P) or differentiation promoting conditions (d). (c) Western blot analysis revealing the expression of NG2 and PDGFR proteins in all three types of cardiac mesoangioblasts. Human mesoangioblasts are shown as positive control. (d) Staining for alkaline phosphatase in clone-derived cells, revealing high activity in most cells of different cardiac mesoangioblasts clones. Bar, $50 \mu \mathrm{m}$. (e) Immunofluorescence analysis showing expression of smooth muscle actin (red) in cardiac mesoangioblasts. Bar, $50 \mu \mathrm{m}$. (f) Double immunofluorescence analysis showing expression of NG2 and/or ANF both in vitro in proliferating (ki67 positive cells) cardiac mesoangioblasts (left and central panel) and in vivo (right panel). Bars, 10 and $100 \mu \mathrm{m}$, respectively. Arrowheads show coexpression of the two markers (g) Double immunofluorescence analysis showing expression of Nkx2.5 (upper panel) and GATA-4 (lower panel) and sarcomeric myosin in cardiac mesoangioblasts. Bar, $50 \mu \mathrm{m}$

(see Supplementary Table 1). Surprisingly, the same clones also expressed at high levels pericyte markers such as NG2 and PDGFR (Figure 2c), alkaline phosphatase (AP) (Figure 2d) and SMA (Figure 2e). We confirmed by immunofluorescence coexpression of NG-2 and ANF in proliferating cardiac mesoangioblasts in vitro as demonstrated by double staining with Ki67 (Figure 2f, left and central panel, respectively). Cells expressing both markers were also found in ventricle sections from wt mice (Figure 2f, right panel). Expression of Nkx2.5 and GATA-4 by myosin-positive cardiac mesoangioblasts was confirmed by immunofluorescence (Figure 2g).

Prospective isolation of cardiac mesoangioblasts from heart explants. In the adult mouse heart, small vessels are composed of endothelium-expressing, among other markers, CD34 and CD31, and surrounding pericytes which express alkaline phosphatase (AP), smooth $\alpha$ actin (SMA) and NG2 proteoglycan (an example of heart tissue stained with antibodies against NG2 and CD31 or CD34 is shown in Figure 3a). A minority of cells was identified by the coexpression of NG2 and CD34 or NG2 and CD31, three of the markers that characterize cardiac mesoangioblasts. To demonstrate that cells with this phenotype are the founders from which clonal populations are derived in vitro, cells outgrown from 10 different ventricle explants, were collected and expanded as a single-cell population and then separated by a fluorescence-activated cell sorter into three different populations, single-positive NG2 +/CD34- or CD34+I NG2 - fractions and a double-positive CD34+/NG2 + fraction (Figure $3 \mathrm{~b}$ ); the percentage of each population were $7.52,5.44$ and 2.31 respectively; only the doublepositive population was able to grow on gelatin-coated plates with a morphology similar to mesoangioblasts (Figure 3c) and to generate a clonal progeny able to differentiate to cardiomyocytes; this double-positive fraction accounted for the $2.1 \%$ of the whole cell population. Cells derived from this fraction and expanded in vitro for 2 weeks were analyzed again for the three markers by flow cytometry and immunofluorescence and appeared to uniformly express NG2, CD31 and CD34 (Figure 3d and e). The remaining experiments were always performed with the double-positive population, while the other two (single-positive) populations were not studied as they were unable to differentiate into cardiomyocytes. When mesoangioblast isolation was attempted by proteolytic digestion, the double-positive 

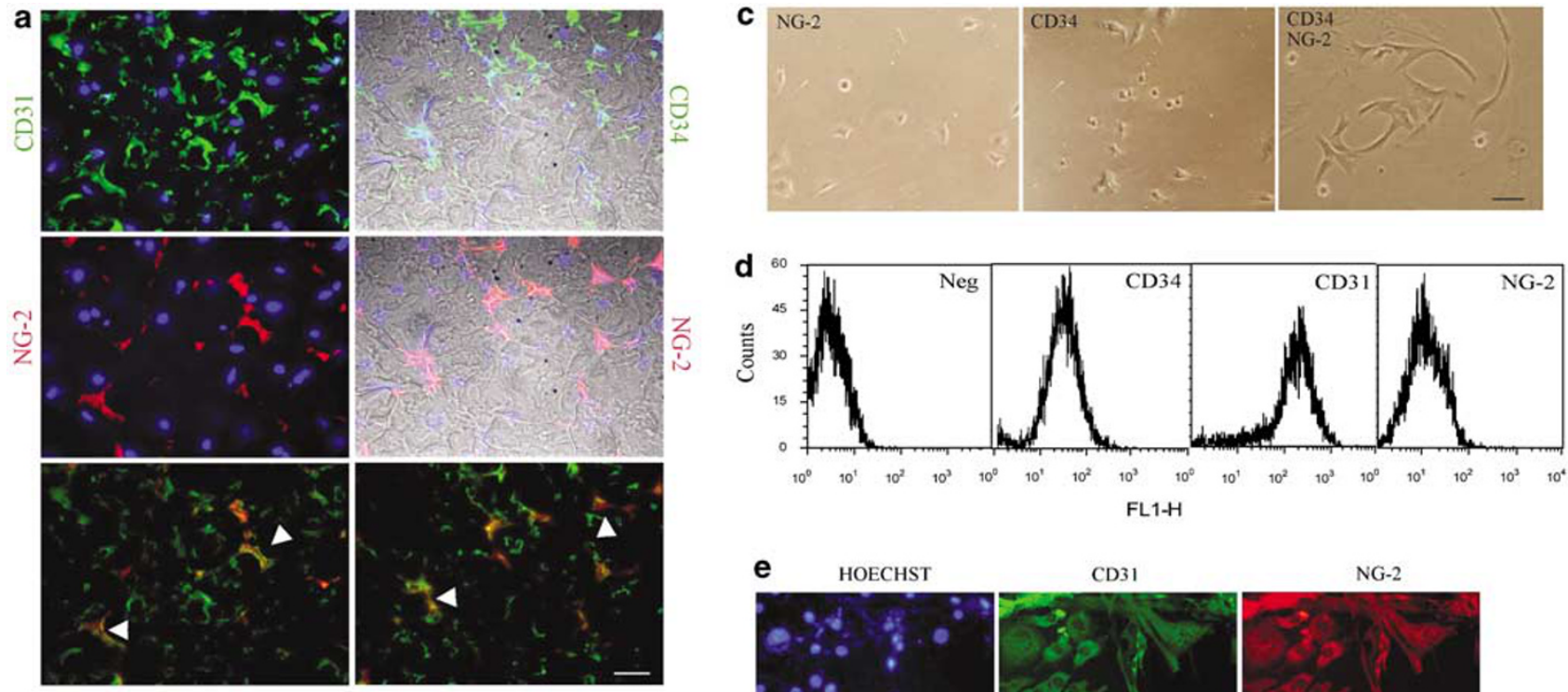

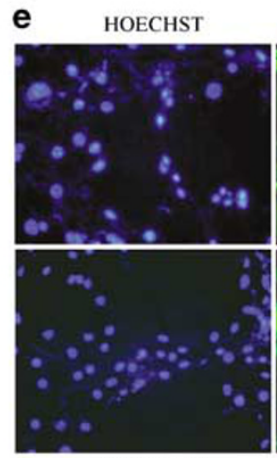

HOECHST

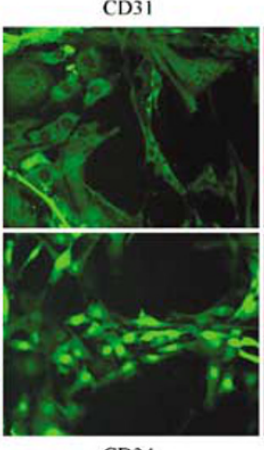

CD34

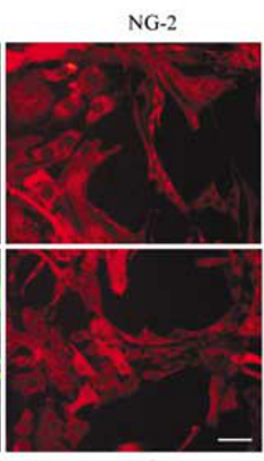

NG-2

Figure 3 Prospective isolation of cardiac mesoangioblasts. (a) Immunofluorescence analysis of ventricle sections stained for NG-2, CD31 and CD34, showing the presence of double positive cells (arrowheads). Bar, $100 \mu \mathrm{m}$. (b) Isolation of the double positive (CD34 + /NG2 +) cell population by fluorescence activated cell sorter. (c) Phase contrast images for the morphology of the different sorted populations. Bar, $50 \mu \mathrm{m}$. (d) Analysis of surface markers expression in the double positive (CD34 +/NG2 +) cell population. (e) Double positive (CD34 + /NG2 +) cell population grown and stained with CD31, CD34 and/or NG2 mAbs. Nuclei are stained with Dapi. Bar, $50 \mu \mathrm{m}$

fraction was dramatically diminished and failed to grow in culture; this likely explains why this cell population had not been identified in previous work, based upon proteolytic digestion.

The explant culture however, may change marker expression and thus the clonogenic CD34 + /NG2 + population isolated in vitro may not correspond to the CD34+1 $\mathrm{NG} 2+$ cells detected in vivo. To avoid any culture manipulation, 50 neonatal hearts were extensively minced, washed to remove blood cells and then dissociated by repeated pipetting (Supplementary Figure 1A). Under this condition a heterogeneous population proliferated and, after 5 days it appeared to be composed of cells expressing either CD34, or NG2 or both (arrowheads) or none (Supplementary Figure 1B). A quantitative analysis of this population (Supplementary Figure $1 \mathrm{C}$ ) revealed that the CD34+/ $\mathrm{NG} 2$ + population represented approximately $2 \%$ of the total, corresponding to the percentage of double-positive cells present in vivo. Alternatively cells were stained for the expression of NG-2 and CD34 and then plated at clonal density in 96 multi wells (examples are shown in Supplementary Figure 1D). After $4 \mathrm{~h}$, plates were scored under and wells containing a single NG2 + or $\mathrm{CD} 34+$, or NG2 + /CD34 + or one negative cell were differentially labeled and multi wells cultured for 10 days. A total of 28 cardiac actin-expressing clones were derived from CD34+/NG2 + founder cells, together with four clone-expressing cardiac actin and VWF and two expressing cardiac actin and calponin; three vWF expressing clones were derived from CD34 + cells and five clones expressing calponin were derived from NG2 + cells (Supplementary Figure 1E). Examples of clones are shown in Supplementary Figure 1F. Together these data show that mesoangioblast clones are derived from a CD34+/NG2 founder cell, presumably located in a perivascular space in vivo.

Differentiation of cardiac mesoangioblasts. We tested the ability of adult cardiac mesoangioblasts to undergo terminal differentiation into cardiomyocytes and other mesoderm cell types. Adult cardiac mesoangioblasts differentiate predominantly to cardiomyocytes, although they maintain the ability to differentiate into smooth muscle cells (up to $30 \%$ of the total population) when treated with TGF- $\beta$. These cells failed to differentiate into osteoblasts, adipocytes and skeletal muscle (less than $5 \%$ of the total population). However, when cocultured with mouse neonatal cardiomyocytes, the large majority of the cells underwent cardiac muscle differentiation, with more 


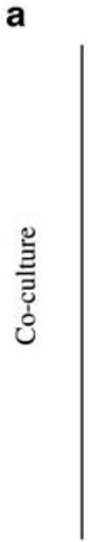
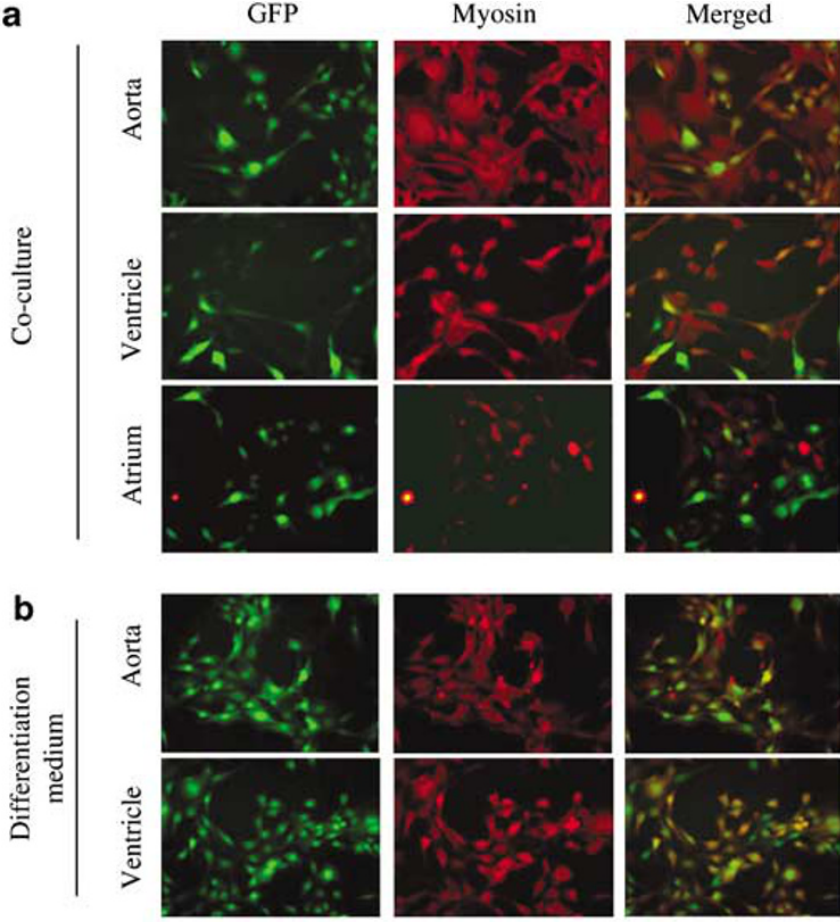

Aorta
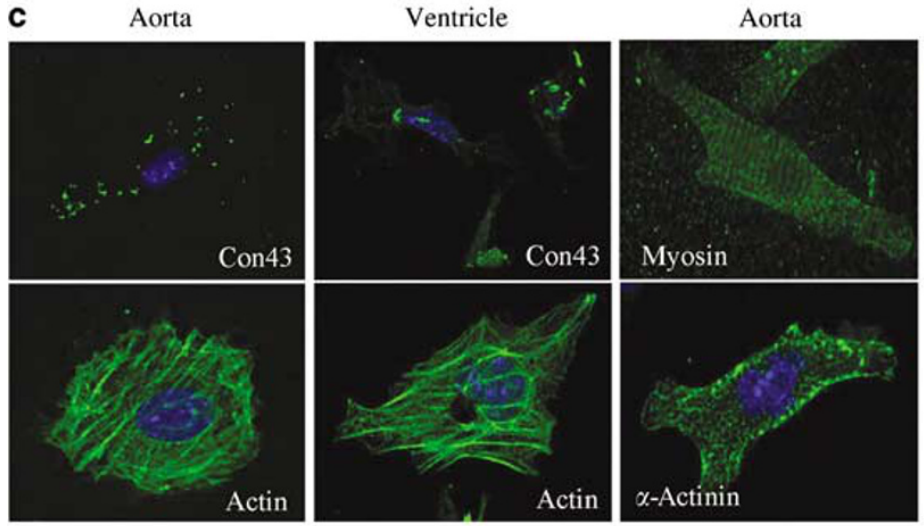

Hoechst
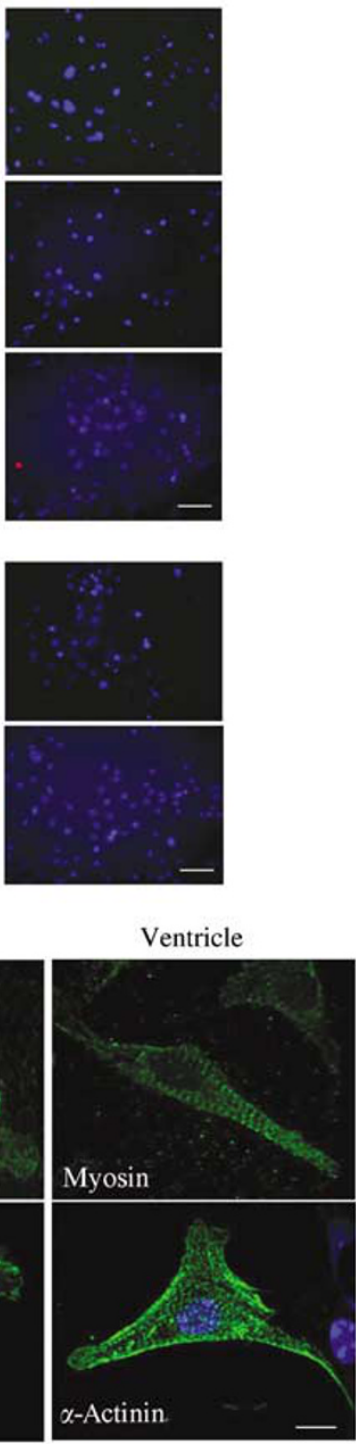

d
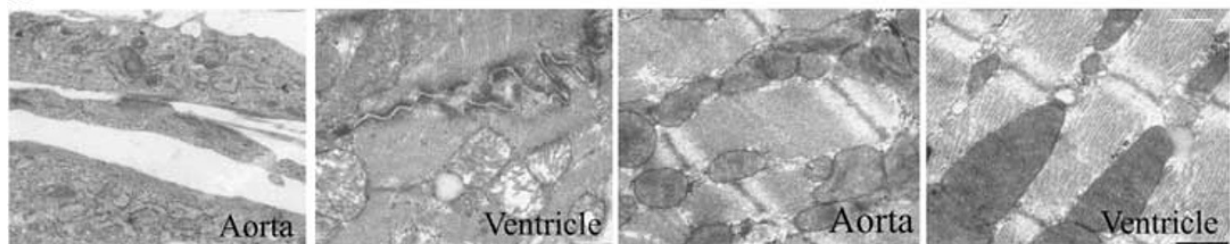

Figure 4 Cardiomyocyte differentiation of cardiac mesoangioblasts. (a) GFP cardiac mesoangioblasts from aorta or ventricle or atrium were co-cultured with wt mouse neonatal cardiomyocytes for five days and then analyzed for the expression of myosin heavy chains, (MyHC) (red). Nuclei were stained with Hoechst. Bar, $50 \mu \mathrm{m}$ (b) GFP aorta or ventricle derived mesoangioblasts were differentiated under low serum, differentiation promoting conditions for five days and analyzed for the presence of MyHC (red). Nuclei were stained with Hoechst as control. Bar, $50 \mu \mathrm{m}$ (c) Aorta and ventricle derived mesoangioblasts were immunostained for the presence of connexin 43 , actin, sarcomeric myosin and $\alpha$-actinin. Note the presence of well-defined sarcomeric structures. Bar, $10 \mu \mathrm{m}$ (d) Electron-microscopy analysis revealed formation of gap junctions and sarcomeric structures in aorta and ventricle mesoangioblasts. Bar, $1 \mu \mathrm{m}$

than $80 \%$ of cells from aorta- and ventricle-expressing sarcomeric myosin (Figure 4a). Atrium mesoangioblasts differentiated into myosin-positive cardiomyocytes at a lower rate (less than 10\%). Unexpectedly, when aorta or ventricle mesoangioblasts were exposed to cardiac differentiation medium (low serum), approximately $70-80 \%$ of cells spontaneously differentiated into myosin-positive cardiomyocytes (Figure 4b). Atrium mesoangioblasts were unable to differentiate in low serum. The percentage of differentiation in different ventricle clones at different passages ranged between 50 and $80 \%$, as shown in Supplementary Table 2. 
Upon differentiation, aorta- and ventricle-derived cardiac mesoangioblasts expressed and localized correctly cardiomyocyte specific proteins such as connexin 43, myosin, actin and $\alpha$-actinin (Figure $4 \mathrm{c}$ ). RT-PCR analysis also revealed expression of cardiac but not skeletal actin, ANF, cardiac Tnl and ventricular myosin heavy and light chains type II (Supplementary Table 1). Electron microscopy revealed gap connections and well developed sarcomeres in cells from the ventricle; in the aorta-derived cells mainly nascent sarcomeres were detected (Figure 4d). It is noteworthy that, both ventricle- and aorta-derived cardiac clones were able to beat as mature cardiomyocytes also when cultured alone (on line Supplementary material: video 1 and 2, respectively).

Functional properties of cardiac mesoangioblasts. We used patch-clamp analysis to evaluate the functional characteristics of ventricle-derived cardiac mesoangioblasts and verify the expression of ion channels underlying electrical activity (Figure 5).

Undifferentiated cells had a depolarized resting potential of $-18.2 \pm 1.3 \mathrm{mV}(n=7)$ and a capacitance of $59.2 \pm 8.2 \mathrm{pF}$ $(n=4)$; the analysis of cardiac mesoangioblasts was performed on isolated, quiescent ventricle-derived cells. The cell capacitance was $40.2 \pm 3.8 \mathrm{pF}$ and the resting potential was $-62.8 \pm 3.7 \mathrm{mV}(n=8)$. Stimulated action potentials (Figure $5 \mathrm{a}$ ) had mean duration at $90 \%$ repolarization (APD90) and amplitude of $83.3 \pm 19.2 \mathrm{~ms}$ and $118 \pm 9.6 \mathrm{mV}$, respectively $(n=8)$; despite cell-to-cell variability, a clear plateau phase, typical of ventricular action potentials, was normally apparent. Representative current traces recorded during different voltage protocols (see Methods) are shown in Figure 5, panels B-E. A fast $\mathrm{Na}+$ current, responsible for the upstroke of the action potential, was recorded in all cells investigated $(n=67)$ (Figure $5 b)$. The time constant of inactivation was $0.60 \pm 0.02 \mathrm{~ms}$ at $-20 \mathrm{mV}(n=5)$. An L-type $\mathrm{Ca} 2+$ current, normally contributing to the plateau, was identified as the nifedipine-sensitive current (10 $\mu \mathrm{M}$ nifedipine) (Figure $5 \mathrm{c}$ ). Inactivation at $-10 \mathrm{mV}$ was analyzed by fitting traces to a double exponential function, and the fast and slow components had time constants of $8.0 \pm 3.9$ and $88.5 \pm 9.4 \mathrm{~ms}$, respectively $(n=4)$. We also found evidence for two $\mathrm{K}+$ currents, an inwardly-rectifying (IK1, Figure 5d) and a depolarization-activated, slow delayed current (I Ks, Figure 5e). The I K1 current was identified as the Ba2+sensitive component during a voltage-ramp protocol applied in Tyrode solution and after addition of $2 \mathrm{mM} \mathrm{BaCl} 2$ (Figure $5 \mathrm{~d}$ ). Averaging from $n=6$ cells, the IK1 current reversed at $-75.2 \pm 1.3 \mathrm{mV}$ and had a mean steady-state amplitude of $-2.4 \pm 0.6 \mathrm{pA} / \mathrm{pF}$ at $-100 \mathrm{mV}(n=6)$. A slow delayed component (IKs, Figure 5e) was identified by dissection with the IKs-specific blocker chromanol 293B $(10 \mu \mathrm{M})$. The mean activation curve of this component had a half activation voltage of $7.7 \mathrm{mV}$ and an inverse slope factor of $13.6 \mathrm{mV}$ ( $n=5$ cells). The ionic currents expressed by cardiac mesoangioblasts have properties similar to those of corresponding currents of newborn or adult mouse ventricular myocytes. ${ }^{11-15}$ This set of currents is perfectly adequate to sustain the electrical activity of cardiac mesoangioblasts and

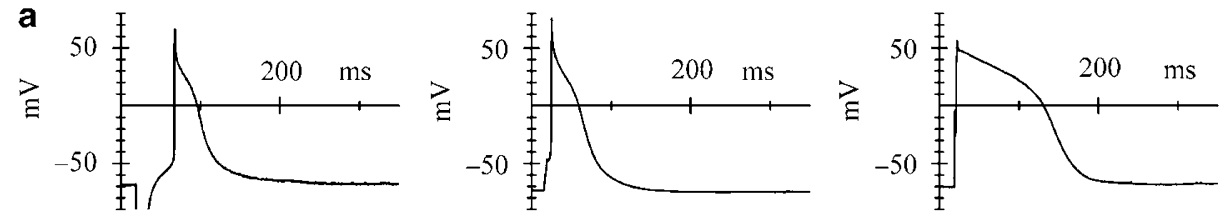

b

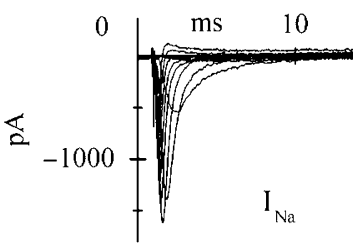

C
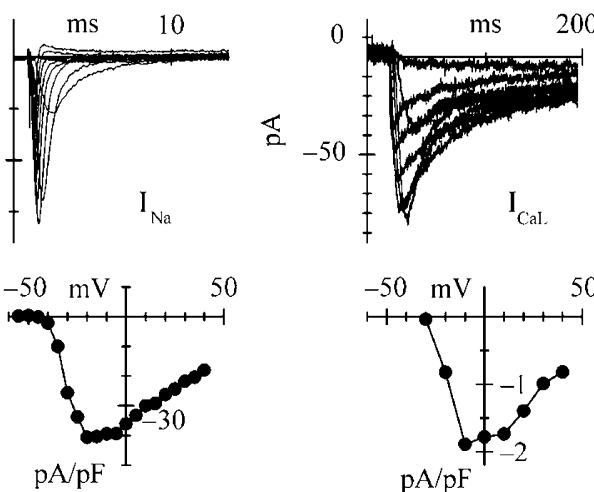

d

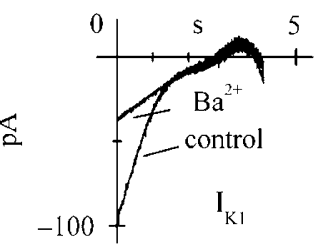

e
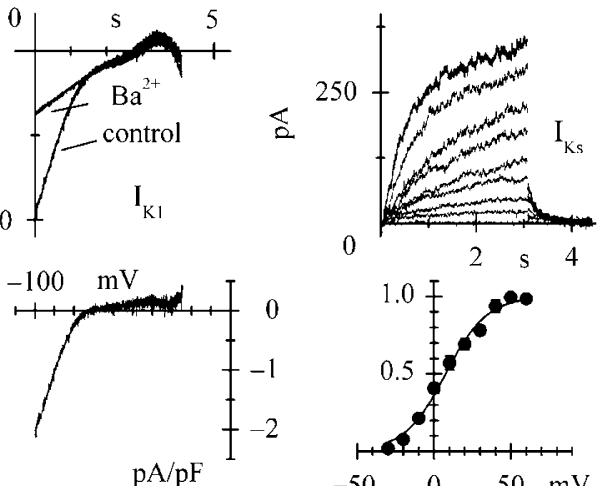

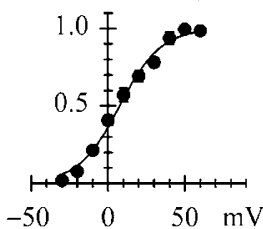

Figure 5 Electrophysiological properties of cardiac mesoangioblasts. (a) representative action potentials recorded in isolated cardiac mesoangioblasts in response to application of brief hyperpolarizing (left) or depolarizing (middle; right) current injections; (b) fast $\mathrm{Na}^{+}$current (l $l_{\mathrm{Na}}$ ) traces recorded during an activation protocol (upper) and corresponding peak I/V relation (lower); (c) L-type $\mathrm{Ca}^{2+}$ current traces $\left(\mathrm{I}_{\mathrm{CaL}}\right)$ during an activation protocol, obtained by subtraction between control traces and traces in the presence of $10 \mu \mathrm{M}$ nifedipine (upper), and corresponding peak I/V curve (lower); (d) steady-state I/V relations measured in a cell with a voltage-ramp protocol in Tyrode solution and during perfusion with $2 \mathrm{mM} \mathrm{BaCl} 2$, as indicated (upper); the $\mathrm{Ba}^{2+}$-difference current $\left(l_{\mathrm{K} 1}\right.$, lower) was strongly rectifying and reversed at about $-72 \mathrm{mV}$ in this cell; (e) slow delayed current traces $\left(\mathrm{I}_{\mathrm{Ks}}\right)$ recorded in a cell during an activation protocol, obtained by subtraction between control traces and traces in the presence of $10 \mu \mathrm{M}$ chromanol 293B (upper); the lower panel shows the mean activation curve (dots) fitted to a Boltzmann equation (full line) 
trigger contraction. Expression of the above current components was specific of cardiac mesoangioblasts following differentiation, and was completely absent in undifferentiated cells $(n=7)$.

In vivo differentiation. Hearts from mice after left coronary artery ligation (CAL) were injected intraventricularly with $3 \times 10^{5}$ cardiac mesoangioblasts and collected after 6 weeks. Before killing, mice were subjected to echocardiography that revealed a doubling of the ventricular wall thickness, a $40 \%$ increase of shortening fraction (from 14 to $23 \%$ ) but no major changes in left ventricular chamber diameter (Supplementary Table 3). These data correlate with the morphological analysis. As shown in Figure 6a, GFP ventricular mesoangioblasts were detected in different regions of the heart (arrowheads show colocalization of GFP with myosin). Further details of the image are shown in Supplementary Figure 2 (separate fluorescence layers) and Supplementary Figure 3 (high magnification of the ventricular wall). Cardiac mesoangioblasts differentiated into well structured cardiomyocytes, which expressed sarcomeric myosin (Figure 6b) and assembled mature sarcomeres inside GFP-positive cells, which were identified by electron dense vacuoles (Grabenbauer et al., 2005), as shown by electron microscopy in Figure 6c. Figure $6 \mathrm{~d}$ shows areas where GFPpositive cells expressed sarcomeric myosin. The same experiment was repeated using cardiac mesoangioblast transduced with a lentiviral vector expressing nuclear LacZ. As shown in Figure 6e, cardiomyocyte nuclei expressed $\beta$-galactosidase. Therefore, cardiac mesoangioblasts can generate new myocardium but mainly at the periphery of the necrotic area. These data indicate that cardiac mesoangioblasts are often less efficient in repairing the infarted heart when compared to other types of cardiac stem progenitor cells. This apparent paradox may depend upon the high cardiac differentiation potency of cardiac mesoangioblasts that likely reduces proliferation, migration

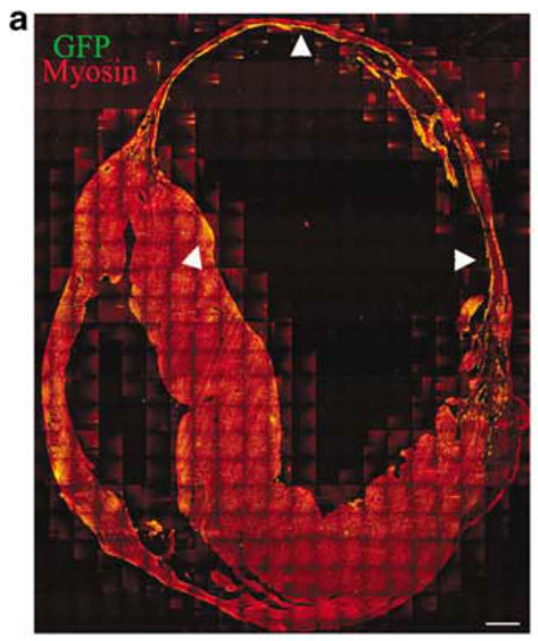

b

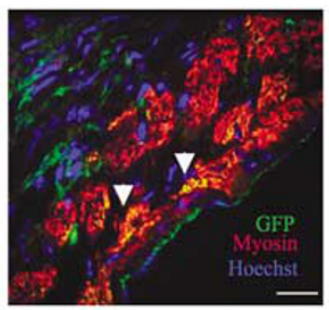

C

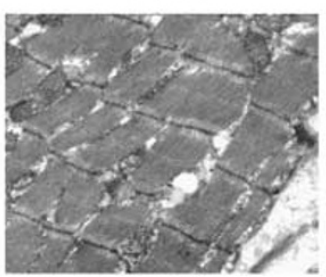

d
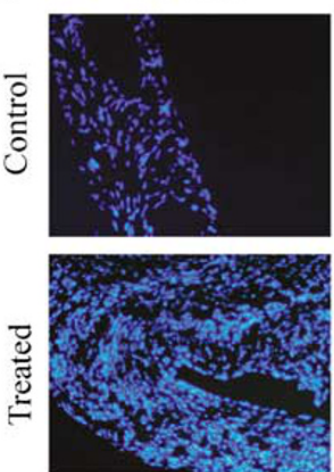

Myosin
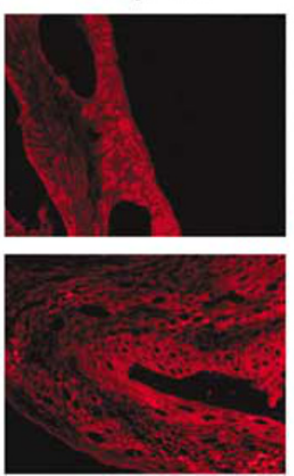

GFP
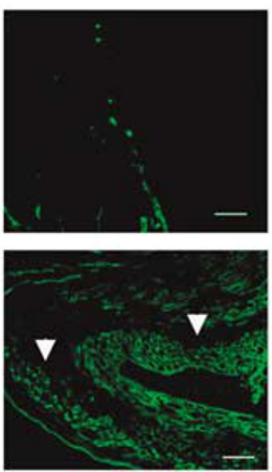

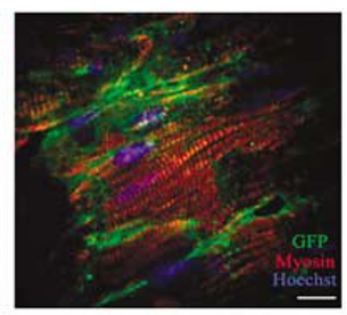

Ventricle

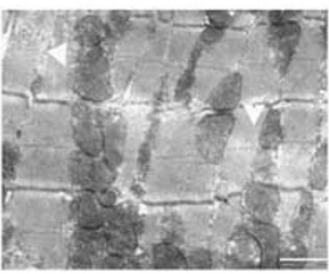

e
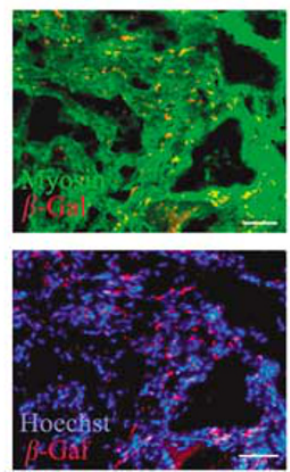

Figure 6 In vivo differentiation of cardiac mesoangioblasts. (a) Mosaic reconstruction of a complete adult heart transverse section, at the level of the ventricle basis (after CAL and mesoangioblast transplantation) showing areas of co-localization between GFP (injected cardiac mesoangioblasts) and MyHC. Note that the inner myocardium in the infarct region has been colonized by GFP + donor cells (orange in the merged image) while the outer layer has not (arrowhead). Bar, $500 \mu \mathrm{m}$. (see also Suppl. Figures 3 and 4). (b) Immunofluorescence analysis showing GFP positive cells that express sarcomeric myosin in well-structured sarcomers at low and high magnification (Bar, 100 and $1 \mu \mathrm{m}$, respectively). (c) Electron microscopy analysis revealing GFP positive cells (recognized by electron dense vesicles) with well-developed sarcomers. Bar, $5 \mu \mathrm{m}$. (d) Immunofluorescence analysis of mouse hearts injected with ventricle derived mesoangioblasts, showing GFP positive cells that also express sarcomeric myosin at low magnification, bar $100 \mu \mathrm{m}$. Large areas throughout the damaged wall could be detected. Immunofluorescence analysis of control hearts (after CAL but no cell transplantation) stained for myosin and GFP (control panels). (e) Double immunofluorescence staining with antibodies against $\beta$ galactosidase and Myosin Heavy chains, revealing LacZpositive cells in the myocardium. Bar, $50 \mu \mathrm{m}$ 
and secretion of paracrine factors such as bFGF, HGF and PDGF that are rather secreted by undifferentiated progenitors (Supplementary Figure 4). Therefore, the main fate of transplanted cells is likely immediate differentiation into a limited number of cardiomyocytes (only $2 \%$ of injected cells, i.e. $\sim 6000$ cells enter the coronary circulation) that cannot cause a dramatic recovery.

To verify whether fusion may occur between transplanted cells and resident cardiomyocytes, we generated cardiac mesoangioblasts from mice-expressing ubiquitous CRE and from the ROSA-Floxed reporter line. Each cell population was injected in the ventricle of the counterpart mice subjected to CAL. After 1 month, we could not detect the presence of any Lac-Z + nuclei cell inside the injected heart (Supplementary Figure 5B). This result is unlikely to depend upon insufficient Cre recombinase activity, since in vitro fusion of cardiac mesoangioblasts with cardiomyocytes was detected albeit at a low frequency (Supplementary Figure 5A). Together these data indicate that fusion is unlikely to be the main mechanism by which mesoangioblasts differentiate into functional cardiomyocytes.

Recently, a multipotent progenitor cell has been identified in the mouse embryonic heart. ${ }^{16,17}$ We therefore tested the ability of adult cardiac mesoangioblasts to colonize and participate in the development of an embryonic chick heart. A pellet of approximately $10^{5}$ ventricle-derived cardiac mesoangioblasts was transplanted in the secondary heart field ${ }^{17}$ of chick embryos at Hamilton Hamburger $(\mathrm{HH})$ stage 8 (three to five somites) (Figure 7a); hearts were collected after 2-7 days ( $\mathrm{HH}$ Stages 21-23 and 30-33) and stained for the coexpression of sarcomeric myosin and $\beta$-galactosidase or GFP, respectively. All transplanted hearts appeared morphologically normal and beating at the time of dissection. As shown in Figure 7b, LacZ-positive cells were clearly visible in six out of 10 freshly dissected embryos at $\mathrm{HH} \mathrm{21-23} \mathrm{and}$ localized mainly in the secondary heart field. Sectioning of these hearts revealed variable colonization of the heart by donor cells (Figure 7d). However, upon staining for GFP or $\beta$-galactosidase and sarcomeric myosin (or CD31 or SMA) all transplanted hearts contained $\beta$-gal or GFP-positive cardiac mesoangioblasts, albeit in variable proportion. Figure $7 \mathrm{e}$ shows a HH33-transplanted heart with $\beta$-gal-positive cells differentiated into myosin-expressing cardiomyocytes. Figure $7 f$ shows transplanted hearts colonized by donor cells that differentiated into cardiac muscle and to a minor extent into endothelium and smooth muscle. At $\mathrm{HH}$ 3033, all transplanted hearts (5/5) also contained GFP-positive donor cells that had differentiated into cardiomyocytes (data not shown). Cardiac differentiation of mouse cells was confirmed by RT-PCR (Figure 7c) that amplified $\alpha$-cardiac actin with mouse-specific oligonucleotides.

\section{Discussion}

A vessel-associated progenitor cell in the heart. In this study, we demonstrate the presence of vessels-associated, self-renewable and committed cardiac progenitors in the heart of juvenile mice. We show that it is possible to isolate a

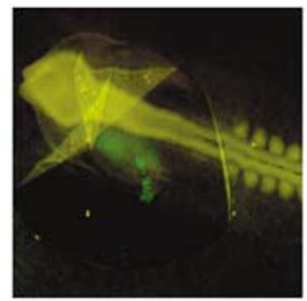

b

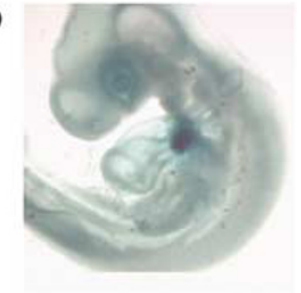

C

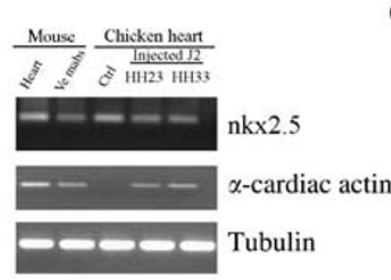

d

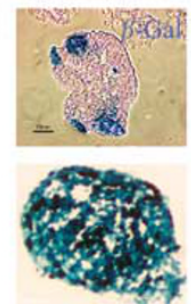

e
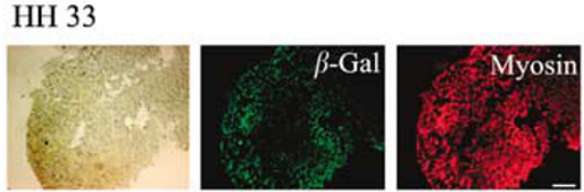

HH 23

f
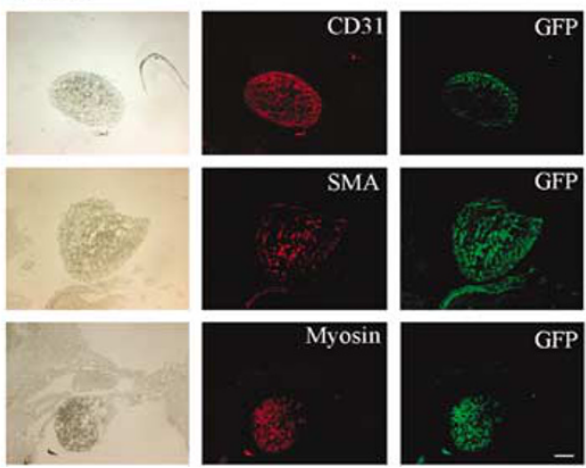

Figure 7 Transplantation of cardiac mesoangioblasts into chick embryos. (a) Fluorescence image (overlayed on phase contrast) showing a pellet of GFP cardiac mesoangioblast implanted in the heart forming region of 5-8 somite embryos. (b) Whole chick embryo at $\mathrm{HH} 23$, visualized under the stereo-microscope showing the pellet of LacZ cardiac mesoangioblasts in the heart region. Bar, $1 \mathrm{~mm}$. (c) RT-PCR for Nkx2.5 (conserved region) and $\alpha$ cardiac actin (mouse specific region) were performed with $\mathrm{CDNA}$ isolated from mouse and chicken hearts, transplanted or not with cardiac mesoangioblasts. (d) X-gal staining of sections from $\mathrm{HH} 23$ heart embryos showing the presence of LacZ + nuclei, detected with at moderate (upper) or high (lower) frequency in the samples shown. Bar, $100 \mu \mathrm{m}$. (e) Double immunofluorescence of $\mathrm{HH} 33$ transplanted heart with $\beta$-gal and myosin antibodies. Bar, $100 \mu \mathrm{m}$. (f) Double immunofluorescence with antibodies against CD31 (upper panel), SMA (middle panel) and MyHC (lower panel), all stained in red, and antiGFP, stained in green, on sections from $\mathrm{HH} 23$ chick embryo heart, after transplantation with GFP ventricle derived cardiac mesoangioblasts. Note widespread distribution of cardiac mesoangioblasts within the newly formed heart. Bar, $100 \mu \mathrm{m}$

these cells from different regions of the heart by nonenzymatic methods and expand them in vitro.

The cells isolated from the explanted tissue fragments and expanded in vitro coexpress endothelial and pericyte markers; they also express cardiac-specific transcription factors and differentiate at very high frequency into beating cardiomyocytes. Because of the origin and phenotype, we termed these 
cells 'cardiac mesoangioblasts'. These cells differ from the human mesoangioblasts, recently described as pericytes of skeletal muscle, ${ }^{9}$ as they coexpress endothelial and pericyte markers, and are committed to cardiac differentiation whereas human pericytes spontaneously differentiate into skeletal myotubes. After intra-ventricular transplantation, cardiac mesoangioblasts migrate to the border of injured myocardium in a coronary artery ligation model, differentiate in vivo into mature cardiomyocytes and partially ameliorate cardiac function. Moreover, despite their origin from adult heart, they retain the ability to colonize embryonic chick heart and participate in morphogenesis.

In the last few years, many groups have isolated different cell types able to differentiate into cardiomyocytes at different but usually low frequency. These include resident cells such as the c-Kit + cardiac stem cells, IsI-1 + and Sca1 + cardiac progenitors and cells originating from the hemo-vascular system such as the endothelial progenitors (EPC), the multipotent adult progenitor cells (MAPC), the hematopoietic SP cells, mesoangioblasts and mesenchymal stem cells. ${ }^{2,4,6,10,18-21}$ Methods of isolation, growth media, donor age and anatomical origin always differ among these different studies and this may explain, at least in part, the high phenotypic variability of the different stem/progenitor cells that have been described so far.

The anatomical niche of cardiac mesoangioblasts. Cardiac mesoangioblasts already express genes required for cardiac differentiation such as Nkx2.5, GATA-4, which distinguish them from other cell types ${ }^{22,23}$ and explain their spontaneous cardiac differentiation upon removal of growth factors. They do not express skeletal myogenic determination genes and are indeed unable to differentiate into skeletal muscle. Interestingly, they express some early endothelial and pericyte markers such as CD31, CD34, NG2 and alkaline phosphatase. This argues for a vascular origin or at least for a close association with the vessel wall; indeed it is possible to localize cells coexpressing endothelial and pericyte markers in the wall of micro-vessels from which they can be prospectively isolated because of this peculiar marker expression (endothelial and pericyte markers are usually mutually exclusive). We hypothesize that during pre- and post-natal development, cells deriving from the incoming vasculature may be recruited to a cardiac fate. In vitro evidence for an endothelialcardiac transdifferentiation was presented in the past. ${ }^{24}$ Support to this hypothesis comes from the ability of both cell types to contribute to chick heart morphogenesis when transplanted in the secondary heart field of $\mathrm{HH}$ stage 8 chick embryos. Cardiac mesoangioblasts differentiate spontaneously at high frequency into beating cardiomyocytes and only to a minor extent into endothelium or smooth muscle, strongly suggesting a progressive restriction of developmental potency.

High cardiac differentiation potency. Cardiac mesoangioblasts can assemble mature sarcomeres and adhesion junctions, as well as by the expression of appropriate ionic channels. Ventricular myocytes from newborn or adult mice typically express a similar array of ion channels with comparable properties. ${ }^{11-15}$ This set of channels is perfectly adequate for the generation of electrical activity, as manifest by the recording of action potentials and of the associated contractile activity (Supplementary videos 1 and 2). It is interesting to note that action potentials recorded in cardiac mesoangioblasts had a clear, if short, plateau phase and were similar in shape and duration to those normally recorded in ventricular myocytes from newborn and/or adult mouse in a similar temperature range. ${ }^{11,12,25}$ Indeed also cardiospheres (Messina et al., 2004) show spontaneous beating in culture, although they grow in spheres; moreover the cardiosphere forming cell, although also derived from heart explants, is selected through a different procedure and indeed expresses different surface antigens. Cardiac mesoangioblasts grow as monolayer culture of cells that can be massively induced to differentiate and provide a source of committed cardiac progenitors for future experiments. Their spontaneous cardiac differentiation is strikingly high especially in those clones derived from the ventricle, ranging from 60 to $80 \%$ of the cell population, depending upon the clone. It is possible that the high work load of the ventricle may have caused an accumulation of progenitors that are slowly utilized throughout post-natal life, which would explain the progressive reduction of these progenitors in aging hearts. Interestingly, all clones already express markers of smooth muscle (which however are shared by immature myocardium) and promptly respond to TGF $\beta$ by activating smooth muscle genes.

Repair of infarcted myocardium. Until now, the use of embryonic stem cells as a tool for cell therapy in the heart has been limited by possible tumorigenicity and the need for immune suppression, although these cells are highly efficient in generating functional cardiomyocytes. ${ }^{26-28}$ The discovery of cardiac mesoangioblasts in the post-natal heart with high cardiomyogenic potential opens a new possibility. Notably, as these cells tend to disappear from older mouse hearts, this therapeutic approach should likely be directed to juvenile cardiac diseases. Colonization of the ventricle wall by these cells and their subsequent differentiation into cardiomyocytes in vivo was demonstrated by electron microscopy and histology. This results in a significant but only partial functional recovery. Interestingly, cardiac mesoangioblasts do not appear to be able to migrate inside the necrotic area for more than a few $\mathrm{mm}$. Coronary artery ligation results in a large trans-mural infarction, and cells may not be able to heal the whole area unless neo-angiogenesis and/or removal of necrotic tissues may allow subsequent migration. Moreover, the rapid cardiac differentiation of these cells may limit their in vivo proliferation and migration as well as the secretion of paracrine factors that have been shown to be crucial to promote survival of residual myocardium and angiogenesis. Thus, other cardiac diseases not resulting in massive necrosis of cardiac tissues, such as hypertrophic or dilated cardiomyopathy, may be better targets for future cell therapy with cardiac mesoangioblasts.

This new isolation method for cardiac mesoangioblasts from juvenile mouse hearts can be used for the isolation of similar cells from the human heart, favoring the generation of committed human cardiac progenitors that could be used in autologous therapies, especially of those progressive cardiac diseases that affect pediatric or juvenile patients. 


\section{Materials and Methods}

Reagents. Anti-GFP, anti-NG2 and anti- $\beta$-galactosidase Abs were purchased from Chemicon (Temecula, CA). MF20, anti-smooth $\alpha$ actin, anti- $\alpha$-sarcomeric actin, anti-connexin-43 and anti-calponin Abs were from Sigma. Anti-Mlc2 and $\alpha$-actinin Abs were obtained from Invitrogen. Anti-PDGF receptor $\beta$ Abs was from Cell Signaling Technologies. For FACS analysis the following antibodies were used CD44, CD34 and CD45 were from BD Biosciences; CD31, Sca-1 and c-kit from ID labs Inc. Anti-ANP Ab was from Santa Cruz Biotechnology (Santa Cruz, CA). AntiNkx2.5, anti-vWF, anti-ki67 and anti-GATA-4 were from Abcam (Cambridge, UK).

Reagents were purchased from Sigma, unless stated otherwise Alexa-488labeling kit was from Molecular probes Inc. (Leiden, Netherlands).

C57BL10 WT mice were purchased from Charles River Laboratories (Wilmington, MA) and Homo-GFP, CRE and RosaFloxP mice were from The Jackson Laboratory (Bar Harbor, Maine). All mice were handled following institutional guidelines.

Cell cultures. Cardiomyocytes were freshly isolated from neonatal rats as previously described ${ }^{7}$ and were cultured in DMEM plus $20 \% \mathrm{FBS}$ and induced to differentiate in DMEM plus $2 \%$ FBS.

Human mesoangioblasts were isolated from muscle explant as previously reported. $^{9}$

Cardiac mesoangioblasts isolation protocols. Hearts isolated from 4 weeks C57 or GFP mice were kept in DMEM w/o FCS, with antibiotics and subdivided in three different pieces: aorta, ventricle and atrium. Each piece was rinsed in PBS with $\mathrm{Ca}+\mathrm{Mg}+$ and sharply dissected into 1-2 mm diameter pieces with a scalpel. Most fragments did contain small vessels (selected under microscope) and were transferred to a Petri dish coated with gelatin $1 \%$ in presence of $20 \%$ FBS-DMEM plus $5 \mathrm{mM}$ glutamine and antibiotics. Other matrices like collagen type-1, fibronectin and matrigel were also tested but were less efficient in promoting cell outgrowth. These heart fragments were cultured for 8-15 days depending on the region and after the initial outgrowth of fibroblast-like cells, small round and refractile cells appeared. This cell population was easily collected by gently pipetting of the original culture, counted and cloned by limited dilution on gelatin $1 \%$ coated $p 96$-well dishes. Different clones were selected by phase contrast morphology (Figure 1) and then characterized by surface markers expression. Further details of the isolation and culture procedure are presented in Supplementary Material.

To separate by FACS cells outgrown from the explants, these were grown for longer periods ( 15 days). Outgrown cells were detached by pipetting, resuspended in $1 \mathrm{ml}$ of a solution containing PBS plus specific antibodies against CD34 and NG2 and sorted by flow cytometry. The final population was plated on gelatin $1 \%$ coated plates and grown as described before. Additional details of the procedure are described in the Supplementary Material section.

In addition, a non enzymatic mechanical isolation protocol was also developed. In all 50 neonatal hearts were extensively minced for $5 \mathrm{~min}$, washed three times with PBS to remove blood cells and then dissociated by repeated pipetting with progressively smaller tips for $15 \mathrm{~min}$ at $4^{\circ} \mathrm{C}$. The suspension was sedimented for $10 \mathrm{~min}$ at $4^{\circ} \mathrm{C}$ and supernatant was collected and cells were plated at either high or clonal density.

Differentiation assays. Differentiation into cardiac cells was induced by coculturing GFP + adult cardiac clones with mouse neonatal cardiomyocytes. Cardiac clones were added at $1: 5$ ratio and cultures were shifted to differentiation medium (DMEM supplemented with $2 \%$ horse serum). After 5 days, cultures were fixed and stained with antibodies against myosin (MF20) and GFP. Nuclei were stained with Hoechst. The percentage of mesoangioblast cardiac differentiation was calculated by counting the number of GFP + /myosin + cells - as percentage of total GFP + cells. Spontaneous differentiation was induced by shifting cells from growth ( $10 \%$ fetal calf serum) medium to differentiation ( $5 \%$ fetal calf serum) medium.

Analysis of cell proliferation. Cardiac clones, cells were plated at $1 \times 10^{4}$ cells $/ \mathrm{cm}^{2}$ in complete DMEM and passed every 5 days. At each passage, the number of cells was counted in triplicate in the hemocytometer.

Caryotype analysis. Cells, plated at $1 / 3$ confluence $72 \mathrm{~h}$ before analysis, were processed with the Karyomax kit (Invitrogen) according to the manufacturer's instructions. For each of the caryotypes analyzed, five different metaphase spreads were examined.

Telomerase activity. Cells at different population doublings were washed once in ice-cold phosphate-buffered saline and two times in wash buffer $(10 \mathrm{~mm}$ HEPES-KOH, pH 7.5; $1.5 \mathrm{~mm} \mathrm{MgCl2;10} \mathrm{mm} \mathrm{KCl;} 1 \mathrm{~mm}$ Dithiothreitol), then centrifuged at 15000 r.p.m. for $5 \mathrm{~min}$ at $4^{\circ} \mathrm{C}$ and quickly frozen in liquid nitrogen. The cell pellets were resuspended in ice-cold lysis buffer $(0.04 \mathrm{M} \mathrm{KCl}, 0.025 \mathrm{M}$ sodium citrate), incubated on ice for $30 \mathrm{~min}$ and centrifuged at 12000 r.p.m. for $20 \mathrm{~min}$ at $4^{\circ} \mathrm{C}$. The protein concentration was determined by Coomassie protein assay. Telomeric repeats amplification protocol (TRAP) assay was performed with the TRAPeze detection kit (Chemicon, USA) according to the manufacturer's instructions. The products were separated by electrophoresis on $12.5 \%$ polyacrylamide gel and visualized with Syber Green I on Gel Doc 2000 (Bio-Rad).

Alkaline phosphatase reaction. For alkaline phosphatase (AP) staining, cultured plates were rinsed with PBS at 10 days of culture, fixed in $4 \%$ formaldehyde at room temperature for $10 \mathrm{~min}$, and stained in the dark for $30 \mathrm{~min}$ in a $0.1 \mathrm{M}$ Tris$\mathrm{HCl}$ solution $(\mathrm{pH} 8.5)$ containing $0.2 \mathrm{mg} / \mathrm{ml}$ of Napthol AS-MX phosphate and $0.6 \mathrm{mg} / \mathrm{ml}$ of Fast Blue BB salt (Sigma).

Gene expression profiling. Total RNA from different cardiac mesoangioblasts was isolated with TRIzol protocol (Invitrogen, Carlsbad, CA, USA) and reverse transcribed by Taqman kit (Platinum Taq DNA polymerase, Invitrogen). RT-PCR for all the samples was performed using the primers listed in Supplementary Table 4 in Supplementary Material.

Western blot. Cardiac mesoangioblasts were lysed directly in Laemmli buffer on ice. Lysates were resolved on 10\% SDS-PAGE under reducing conditions, and proteins were transferred to nitrocellulose membrane (Hybond-ECL, Amersham Biosciences, Piscataway, NJ, USA). Membranes were revealed with anti-tubulin, anti-NG2 or anti-PDGFR Abs.

Flow cytometry. Cardiac mesoangioblasts were detached with PBS plus $5 \mathrm{mM}$ EDTA on ice and incubated with FITC/TRICT pre-conjugated antibodies against the different surface molecules for $30 \mathrm{~min}$ at $4^{\circ} \mathrm{C}$. Cells were then washed and fluorescent samples were analyzed in a FACSCalibur flow cytometer. At least 10000 events for each sample were counted (Beckton Dickinson, Lincoln Park, NJ, USA).

Cell transduction with lentiviral vectors. Cells were transduced with third generation lentiviral vectors expressing LacZ or nuclear LacZ as previously described (Sampaolesi et al., 2003).

Inmunohistology and immunofluorescence. Clones were grown on gelatin $1 \%$ coated coverslips, washed with PBS and fixed with $4 \%$ paraformaldehyde for $10 \mathrm{~min}$. Cells were then stained with antibodies against different molecules for $30 \mathrm{~min}$ room temperature and then, revealed with antispecies-specific secondary antibodies for $20 \mathrm{~min}$. Images were taken with a $\$ 100$ TV microscope (Carl Zeiss Microlmaging Inc.) or the Leica CTR 6000 microscope for the confocal images.

For morphological EM study, cells were fixed with 4\% PFA and $0.5 \%$ glutaraldehyde in PBS and embedded in Spurrs' resin. Ultrathin sections were stained with uranyl acetate and lead citrate before being observed with a transmission electronic microscope. For fresh tissues and GFP detection, samples were processed as described before (Grabenbauer et al., 2005).

For histology, mice previously injected in the LV chamber with 300000 ventricle cardiac mesoangioblasts, were killed 6 weeks after injection and hearts were quickly frozen in OCT. Serial heart sections were fixed with $4 \%$ PFA, permeabilized with $0,1 \% \mathrm{Tx}-100$, rinsed with $1 \% \mathrm{BSA}$ in PBS and immunostained with anti-GFP, antimyosin, anti-CD31, anti-CD34 or anti- $\beta$-galactosidase Abs. Alexa 488 or 594 (Molecular Probes, Eugene, OR, USA) were used as secondary staining $\mathrm{Ig}$ and Hoechst for nuclear staining. Images were taken with a S100 TV microscope (Carl Zeiss Microlmaging Inc.) or with the Leica CTR 6000 microscope for the confocal images or with inverted deconvolution microscope DeltaVision RT for the paneling image.

Mouse transplantation. Approximately $3 \times 10^{5}$ ventricle cardiac mesoangioblasts were injected into the ventricle of coronary artery ligated mice. ${ }^{7}$ 
Mice were anesthetized with an intraperitoneal injection of physiologic saline $(10 \mathrm{ml}$ $\mathrm{kg}$ ) containing ketamine $(5 \mathrm{mg} / \mathrm{ml})$ and xylazine $(1 \mathrm{mg} / \mathrm{ml})$. Cells were injected in the $\mathrm{LV}$ chamber via a $0.20-\mathrm{mm}$-diameter needle. The blood flow was not stopped before or during this procedure. There was no visible damage to the vessel wall during or after operation. The body wall muscle was closed with sutures and the skin with surgical staples. Animals were killed at 6 weeks after the injection.

Chicken transplantation. Pellet-containing GFP or LacZ ventricle cardiac mesoangioblasts were transplanted into the anterolateral plate mesoderm region of $\mathrm{HH}$ stage eight chicken embryos. After 27 days, chickens were killed and hearts were collected and mounted in OCT for histology, both for immunofluorecence or for $\beta$-galactosidase reaction (Condorelli et al., 2001) or processed for RNA extraction and PCR

Echocardiography. Transthoracic echocardiography (Aloka SSD-5500, Tokio, Japan) was performed on conscious, previously trained mice, 6 weeks after cell transplant with the use of a $13 \mathrm{MHz}$ linear transducer at high frame rate imaging $(102 \mathrm{~Hz})$. The left ventricle was imaged in both parasternal long-axis and short axis views, M-mode tracings and cine loops of two dimensional (2D) echocardiography were recorded on magneto-optic disk for off-line analysis by a sonographer blind to study treatments. Anterior and posterior end-diastolic and endsystolic wall thicknesses and LV internal dimensions were measured and fractional shortening (FS) was calculated as recommended by the American Society of Echocardiography. ${ }^{29,30}$

Data analysis. All data are presented as mean \pm S.E.M. Between-groups analysis of variance was followed by Dunnett's test for post hoc comparisons with CAL control as reference group.

Electrophysiology. For electrophysiological analysis, mesoangioblasts were cultured at low density in $35 \mathrm{~mm}$ Petri dishes and differentiated towards a cardiac phenotype. Patch-clamp analysis was performed on cells perfused with a normal Tyrode solution containing (mM): $140 \mathrm{NaCl}, 5.4 \mathrm{KCl}, 1.8 \mathrm{CaCl}_{2}, 5.5 \mathrm{D}$-glucose, 5 Hepes- $\mathrm{NaOH}$; $\mathrm{pH}$ 7.4. Patch pipettes were filled with a solution containing $(\mathrm{mM})$ $130 \mathrm{~K}$-Aspartate, $10 \mathrm{NaCl}, 5 \mathrm{EGTA}-\mathrm{KOH}, 2 \mathrm{CaCl}_{2}, 2 \mathrm{MgCl}_{2}$, 2 ATP (Na-salt), five creatine phosphate, $0.1 \mathrm{GTP}$ (Na-salt), $10 \mathrm{Hepes}-\mathrm{KOH} ; \mathrm{pH} 7.2$ and had resistances of 2-4 M $\Omega$. Temperature was $36^{\circ} \mathrm{C}$.

The fast $\mathrm{Na}^{+}$current $\left(I_{\mathrm{Na}}\right)$ was activated by $50 \mathrm{~ms}$ steps to the range $-55 /$ $+40 \mathrm{mV}$ from a holding potential of $-60 \mathrm{mV}$. Peak I-V relations were constructed by plotting the peak current, normalized to cell capacitance, against test voltages

The time-independent inwardly-rectifying $\mathrm{K}^{+}$current $\left(\mathrm{I}_{\mathrm{K} 1}\right)$ was investigated by applying $4 \mathrm{~s}$ voltage-ramps from -100 to $-25 \mathrm{mV}$ in Tyrode solution and afte addition of $\mathrm{Ba}^{2+}\left(2 \mathrm{mM} \mathrm{BaCl}_{2}\right)$, a known blocker of $\mathrm{I}_{\mathrm{K} 1}$.

To investigate delayed $\mathrm{K}^{+}$currents we applied depolarizing steps from a holding potential of $-40 \mathrm{mV}$ and used pharmacological dissection by means of componentspecific blockers.

The slow delayed $\mathrm{K}^{+}$current $\left(\mathrm{I}_{\mathrm{Ks}}\right)$ was investigated by applying $3 \mathrm{~s}$ steps to the range $-30 /+50 \mathrm{mV}$ in Tyrode solution and after addition of chromanol 293B $(10 \mu \mathrm{M})$; IKs traces were obtained by subtraction of currents in the presence of the blocker from control currents. Activation curves were obtained by plotting normalized tail currents recorded during decay at $-40 \mathrm{mV}$, and analyzed with the Boltzmann equation: $y=(1 /(1+\exp ((V-V 1 / 2) / s)$, where $y$ is fractional activation, $V$ is voltage, $V 1 / 2$ the half-activation voltage, and $s$ the inverse slope factor.

The rapid delayed $\mathrm{K}^{+}$current $\left(\mathrm{l}_{\mathrm{Kr}}\right)$ was investigated by applying a similar voltage protocol with $250 \mathrm{~ms}$-long steps, and using E4031 $(5 \mu \mathrm{M})$ as specific blocker. During delayed $\mathrm{K}^{+}$current protocols, all solutions contained nifedipine $10 \mu \mathrm{M}$ to block overlapping $\mathrm{Ca}^{2+}$ components.

The L-type $\mathrm{Ca}^{2+}$ current was investigated using perforated patch analysis. To minimize contaminating currents, patch pipettes were filled with a solution containing (mM): 80 aspartic acid, $10 \mathrm{NaCl}, 70 \mathrm{CsOH}, 40 \mathrm{CsCl}, 2.0 \mathrm{MgCl}_{2}, 10$ EGTA, 10 HEPES, 2.0 ATP (Na-salt), 0.1 GTP (Na-salt), amphotericin B $(250 \mu \mathrm{g}$ $\mathrm{ml}$, Sigma); $\mathrm{pH}$ 7.2. Extracellular solution contained (mM): $135 \mathrm{NaCl}, 10 \mathrm{CsCl}, 1$ $\mathrm{CaCl}_{2}, 1 \mathrm{MgCl}_{2}, 5$ HEPES, 10 glucose, and 0.01 tetrodotoxin (TTX); $\mathrm{pH}$ 7.4. $\mathrm{I}_{\mathrm{CaL}}$ was activated by $200 \mathrm{~ms}$ steps to the range $-30 /+40 \mathrm{mV}$ from a holding potential of $-40 \mathrm{mV}$ and dissected by subtracting corresponding traces obtained before and after addition of nifedipine $10 \mu \mathrm{M}$.
Acknowledgements. This work was supported by grants from Fondation Leducq, European Community (European Vascular Genomics Network, Heart Repair, Nax and Normacor), Italian Ministries of Health and Research, Firb and CARIPLO. Beatriz G Galvez was supported by a Program $3+3$ Fellowship from the Centro Nacional de Investigaciones Cardiovasculares (CNIC), Spain. We thank the microscope service of the san Raffaele foundation for help with the images.

1. Olson E. A decade of discoveries in cardiac biology. Nat Med 2004; 10: 467-474.

2. Beltrami A, Barlucchi L, Torella D, Baker M, Limana F, Chimenti S et al. Adult cardiac stem cells are multipotent and support myocardial regeneration. Cell 2003; 114: 763-776.

3. Oh H, Bradfute S, Gallardo T, Nakamura T, Gaussin V, Mishina Y et al. Cardiac progenitor cells from adult myocardium: Homing, differentiation, and fusion after infarction. Proc Natl Acad Sci USA 2003; 100: 12313-12318.

4. Laugwitz K, Moretti A, Lam J, Gruber P, Chen Y, Woodard S et al. Postnatal isl1+ cardioblasts enter fully differentiated cardiomyocyte lineages. Nature 2005; 433: 647-653.

5. Messina E, Angelis LD, Frati G, Morrone S, Chimenti S, Fiordaliso F et al. Isolation and expansion of adult cardiac stem cell from human and murine heart. Circ Res 2004; 95: 911-921.

6. Kocher A, Schuster M, Szabolcs M, Takuma S, Burkhoff D, Wang J et al. Neovascularization of ischemic myocardium by human bone-marrow-derived angioblasts prevents cardiomyocyte apoptosis, reduces remodeling and improves cardiac function. Nat Med 2001; 7: 430-436.

7. Galli D, Innocenzi A, Staszewsky L, Zanetta L, Sampaolesi M, Bai A et al. Mesoangioblasts, vessel-associated multipotent stem cells, repair the infarcted heart by multiple cellular mechanisms. Arterioscler Thromb Vasc Biol 2005; 25: 692-697.

8. Sampaolesi M, Blot S, D'Antona G, Granger N, Tonlorenzi R, Innocenzi A et al. Mesoangioblast stem cells ameliorate muscle function in dystrophic dogs. Nature 2006; 444: $574-579$.

9. Dellavalle A, Sampaolesi M, Tonlorenzi R, Tagliafico E, Sacchetti B, Perani L et al. Pericytes of human skeletal muscle are myogenic precursors, distinct from satellite cells, and efficiently repair dystrophic muscle. Nat Cell Biol 2007; 9: 255-267.

10. Minasi M, Riminucci M, Angelis LD, Borello U, Berarducci B, Innocenzi A et al. The mesoangioblast: a multipotent, self-renewing cell that originates from the dorsal aorta and differentiates into most mesodermal tissues. Development 2002; 129: 2773-2783.

11. Nuss HB, Marban E. Electrophysiological properties of neonatal mouse cardiac myocytes in primary culture. J Physiol 1994; 479: 265-279.

12. Protas L, Barbuti A, Qu J, Rybin VO, Palmiter RD, Steinberg SF et al. Neuropeptide $Y$ is an essential in vivo developmental regulator of cardiac ICa L. Circ Res 2003; 93: 972-979.

13. Brunet S, Aimond F, Li H, Guo W, Eldstrom J, Fedida D et al. Heterogeneous expression of repolarizing, voltage-gated $\mathrm{K}+$ currents in adult mouse ventricles. J Physiol 2004; 559: 103-120.

14. Wang L, Feng ZP, Kondo CS, Sheldon RS, Duff HJ. Developmental changes in the delayed rectifier K+ channels in mouse heart. Circ Res 1996; 79: 79-85.

15. Takemura H, Yasui K, Opthof T, Niwa N, Horiba M, Shimizu A et al. Subtype switching of LType Ca2+ channel from Cav1.3 to Cav1.2 in embryonic murine ventricle. Circ J 2005; 69: 1405-1411.

16. Moretti A, Caron L, Nakano A, Lam J, Bernshausen A, Chen Y et al. Multipotent embryonic $I s / 1^{+}$progenitor cells lead to cardiac, smooth muscle, and endothelial cell diversification. Cell 2006; 127: 1151-1165.

17. Wu S, Fujiwara Y, Cibulsky S, Clapham D, Lien C, Schultheiss T et al. Developmental origin of a bipotential myocardial and smooth muscle cell precursor in the mammalian heart. Cell 2006; 127: 1137-1150.

18. Badorff C, Brandes R, Popp R, Rupp S, Urbich C, Aicher A et al. Transdifferentiation of blood-derived human adult endothelial progenitor cells into functionally active cardiomyocytes. Circulation 2003; 107: 1024-1032.

19. Nygren J, Jovinge S, Breitbach M, Sawen P, Roll W, Hescheler J et al. Bone marrowderived hematopoietic cells generate cardiomyocytes at a low frequency through cell fusion, but not transdifferentiation. Nat Med 2004; 10: 494-501.

20. Zhang S, Wang D, Estrov Z, Raj S, Willerson J, Yeh E. Both cell fusion and transdifferentiation account for the transformation of human peripheral blood CD34positive cells into cardiomyocytes in vivo. Circulation 2004; 110: 3803-3807.

21. Orlic D, Kajstura J, Chimenti S, Jakoniuk I, Anderson S, Li B et al. Bone marrow cells regenerate infarcted myocardium. Nature 2001; 410: 701-705.

22. Durocher D, Charron F, Warren R, Schwartz R, Nemer M. The cardiac transcription factors Nkx2.5 and GATA-4 are mutual cofactors. EMBO 1997; 16: 5687-5696.

23. Kitajima S, Takagi A, Inoue T, Saga Y. MesP1 and MesP2 are essential for the development of cardiac mesoderm. Development 2000; 127: 3215-3226.

24. Condorelli G, Borello U, Angelis LD, Latronico M, Sirabella D, Coletta M et al. Cardiomyocytes induce endothelial cells to tras-differentiate into cardiac clones: implications for myocardium regeneration. Proc Natl Acad Sci USA 2001; 98: 10733-10738.

25. Wang $T, X u Z$, Jiang $W, M a A$. Cell-to-cell contact induces mesenchymal stem cell to differentiate into cardiomyocyte and smooth muscle cell. Int J Cardiol 2006; 109: 74-81.

26. Kolossov E, Bostani T, Roell W, Breitbach M, Pillekamp F, Nygren J et al. Engrafment of engineered ES cell-derived cardiomyocytes but not BM cells restores contractile function to the infarcted myocardium. J Exp Med 2006; 203: 2315-2327. 
27. Kehat I, Kenyagin-Karsenti D, Snir M, Segev H, Amit M, Gepstein A et al. Human embryonic stem cells can differentiate into myocytes with structural and functional properties of cardiomyocytes. J Clin Invest 2001; 108: 407-414.

28. Menard C, Hagege A, Agbulut O, Barro M, Morichetti M, Brasselet C et al. Transplantation of cardiac-committed mouse embryonic stem cells to infarcted sheep myocardium: a preclinical study. Lancet 2005; 366: 1005-1012.
29. Sahn DJ, De Maria A, Kisslo J, Weyman A. Recommendations regarding quantitation in M-mode echocardiography; results of a survey of echocardiographic measurements. Circulation 1978; 58: 1072-1083.

30. Schiller NB, Shah PM, Crawford M, De Maria A, Devereux R, Feigenbaum $\mathrm{H}$ et al. Recommendations for quantitation of the left ventricle by two-dimensional echocardiography American Society of Echocardiography Committee on Standards, subcommittee on Quantitation of Two Dimensional Echocardiograms. J Am Soc Echocardiogr 1989; 2: 358-367.

Supplementary Information accompanies the paper on Cell Death and Differentiation website (http://www.nature.com/cdd) 